Ann. Geophysicae 16, 754-763 (1998) @ EGS - Springer-Verlag 1998

\title{
Simultaneous ionospheric and magnetospheric observations of azimuthally propagating transient features during substorms
}

\author{
T. K. Yeoman ${ }^{1}$, T. Mukai ${ }^{2}$, T. Yamamoto ${ }^{2}$ \\ ${ }^{1}$ Department of Physics and Astronomy, University of Leicester, University Road, Leicester, LE1 7RH, UK \\ ${ }^{2}$ Institute of Space and Astronautical Science, Yoshinodai 3-1-1, Sagamiharashi, Kanagawa 229, Japan
}

Received: 10 September 1997 / Revised: 2 February 1998 / Accepted: 12 February 1998

\begin{abstract}
During the $6^{\text {th }}$ August 1995, the CUTLASS Finland HF radar ran in a high time resolution mode, allowing measurements of line-of-sight convection velocities along a single beam with a temporal resolution of $14 \mathrm{~s}$. Data from such scans, during the substorm expansion phase, revealed pulses of equatorward flow exceeding $\sim 600 \mathrm{~m} \mathrm{~s}^{-1}$ with a duration of $\sim 5 \min$ and a repetition period of $\sim 8 \mathrm{~min}$. Each pulse of enhanced equatorward flow was preceded by an interval of suppressed flow and enhanced ionospheric Hall conductance. These transient features, which propagate eastwards away from local midnight, have been interpreted as ionospheric current vortices associated with fieldaligned current pairs. The present study reveals that these ionospheric convection features appear to have an accompanying signature in the magnetosphere, comprising a dawnward perturbation and dipolarisation of the magnetic field and dawnward plasma flow, measured in the geomagnetic tail by the Geotail spacecraft, located at $L=10$ and some four hours to the east, in the postmidnight sector. These signatures are suggested to be the consequence of the observation of the same field aligned currents in the magnetosphere. Their possible relationship with bursty Earthward plasma flow and magnetotail reconnection is discussed.
\end{abstract}

Key words. Ionosphere (Auroral, ionosphere) · Magnetospheric Physics (Magnetotail; Storms and substorms)

\section{Introduction}

High frequency (HF) ionospheric radars have proved to be a successful technique for investigating the spatial

Correspondence to: T. K. Yeoman and temporal development of the ionospheric conductivities and electric field in the auroral electrojets, which are known to be highly time-dependent (e.g. Kirkwood et al., 1988) and which combine to produce the characteristic ground magnetic perturbations during the substorm expansion phase. Dynamic electrojet behaviour, in which ionospheric flows were suppressed to values as low as $50 \mathrm{~m} \mathrm{~s}^{-1}$ and accelerated up to values as high as $1 \mathrm{~km} \mathrm{~s}^{-1}$, has been observed within a few minutes, accompanied by conductance variations between 20 and $100 \mathrm{~S}$ (Morelli et al., 1995), whilst Yeoman and Pinnock (1996) observed the evolution of the overall convection pattern on a time scale of only $\sim 10$ minutes. Recent high time resolution (14 s) data from HF radars during the highly dynamic substorm expansion phase has revealed a new class of transient convection features during the substorm expansion phase and has related these signatures to the local ground magnetic field measurements (Yeoman and Lühr, 1997, hereafter referred to as Paper 1). Paper 1 revealed short intervals of suppressed flow, followed by the observation of pulses of more intense equatorward ionospheric flows, exceeding $\sim 600 \mathrm{~m} \mathrm{~s}^{-1}$. These pulses had a duration of 3$5 \mathrm{~min}$ and a repetition period of $\sim 8 \mathrm{~min}$. Their spatial extent in the CUTLASS field of view was $400-500 \mathrm{~km}$ in longitude, and $300-400 \mathrm{~km}$ in latitude. They were interpreted as signatures of azimuthally propagating ionospheric current vortices associated with pairs of field aligned currents. These observations of propagating regions of vortical ionospheric flow are analogous to those seen during the substorm recovery phase in an $\Omega$ band (e.g. Lühr and Schlegel, 1994). They are also somewhat similar to the flows expected in the dayside ionosphere in association with flux transfer events (e.g. Lockwood et al., 1990) and the flows associated with dayside travelling convection vortex events (Lühr et al., 1996 and references therein).

In the present study HF radar and ground magnetometer measurements of transient features within the ionospheric convection and the auroral electrojets are combined with magnetic field and plasma data from 
$\sim 10 R_{E}$ downtail made by the Geotail spacecraft. This suggests the existence of related transient features in the magnetosphere.

\section{Instrumentation}

The ionospheric convection velocities in this study are provided by the Finland radar of the Co-operative UK Twin-Located Auroral Sounding System (CUTLASS). CUTLASS is a bistatic HF coherent radar, with stations in Finland and Iceland, and forms part of the international SuperDARN chain of HF radars (Greenwald et al., 1995). The radars form 16 beams of separation $3.24^{\circ}$. Each beam is gated into 75 range bins, each of length $45 \mathrm{~km}$ in standard operations. During standard operations the dwell time for each beam is $7 \mathrm{~s}$, giving a full 16 beam scan, covering $52^{\circ}$ in azimuth and over $3000 \mathrm{~km}$ in range (an area of over $4 \times 10^{6} \mathrm{~km}^{2}$ ), every 2 min. For this interval the Finland radar was operating a non-standard scan mode. In this mode, rather than the usual anticlockwise sweep through beams 15, 14, $13, \ldots, 0$ the sequence $15,9,14,9,13,9, \ldots, 1,9,0$, 9 was employed. This allows the construction of full 16 beam scans at a reduced temporal resolution of $4 \mathrm{~min}$, in addition to the provision of high time resolution (14 s) data along a single look direction (in this case beam 9 , a beam which approximately overlies the main meridional chain of the IMAGE array). This data set is supplemented here by data from ground magnetometers, provided by stations from two arrays, the UK SubAuroral Magnetometer Network (SAMNET) (Yeoman et al., 1990), and the International Monitor for Auroral Geomagnetic Effects, IMAGE) (Lühr, 1994). The instruments are fluxgate magnetometers. SAMNET has a sampling interval of $5 \mathrm{~s}$ and the IMAGE array has $10 \mathrm{~s}$ sampling for the interval under consideration here. The IMAGE data is presented in $X, Y, Z$ co-ordinates, where $X$ is geographic northwards, $Y$ geographic eastwards and $Z$ is vertically downwards. All data have had a quiet day mean subtracted. The field-of-view of the CUTLASS Finland radar, together with the locations of the ground magnetometers used in this study, are illustrated in Fig. 1. In Fig. 1 the magnetic local times of the instrumentation at 21:00 UT are as follows: the western SAMNET stations lie at 21:30 MLT; JAN lies at 22:00 MLT; the main meridional chain of IMAGE lies at $\sim 23: 30$ MLT; the radar backscatter observed in beam 9 of CUTLASS Finland extends over an MLT of 23:25-23:40. Geotail lies 4 h east of the main ground instrumentation at 03:30 MLT.

At 21:00 UT on August $6^{\text {th }} 1995$, Geotail was at a location of $X=-9.8 R_{E}, Y=-10.5 R_{E}, Z=0.8 R_{E}$ in GSM co-ordinates. Data from two Geotail instruments are used here. Spin-averaged vector magnetic field data with a time resolution of $\sim 3 \mathrm{~s}$ are obtained from the MGF instrument (Kokubun et al., 1994) and ion drift, density and temperature data are provided by the Low-Energy Particle instrument (LEP, Mukai et al., 1994) once every four spin periods (a time resolution of $\sim 12 \mathrm{~s})$. The location of the Geotail spacecraft is

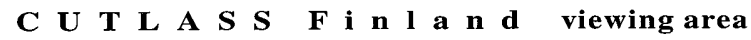

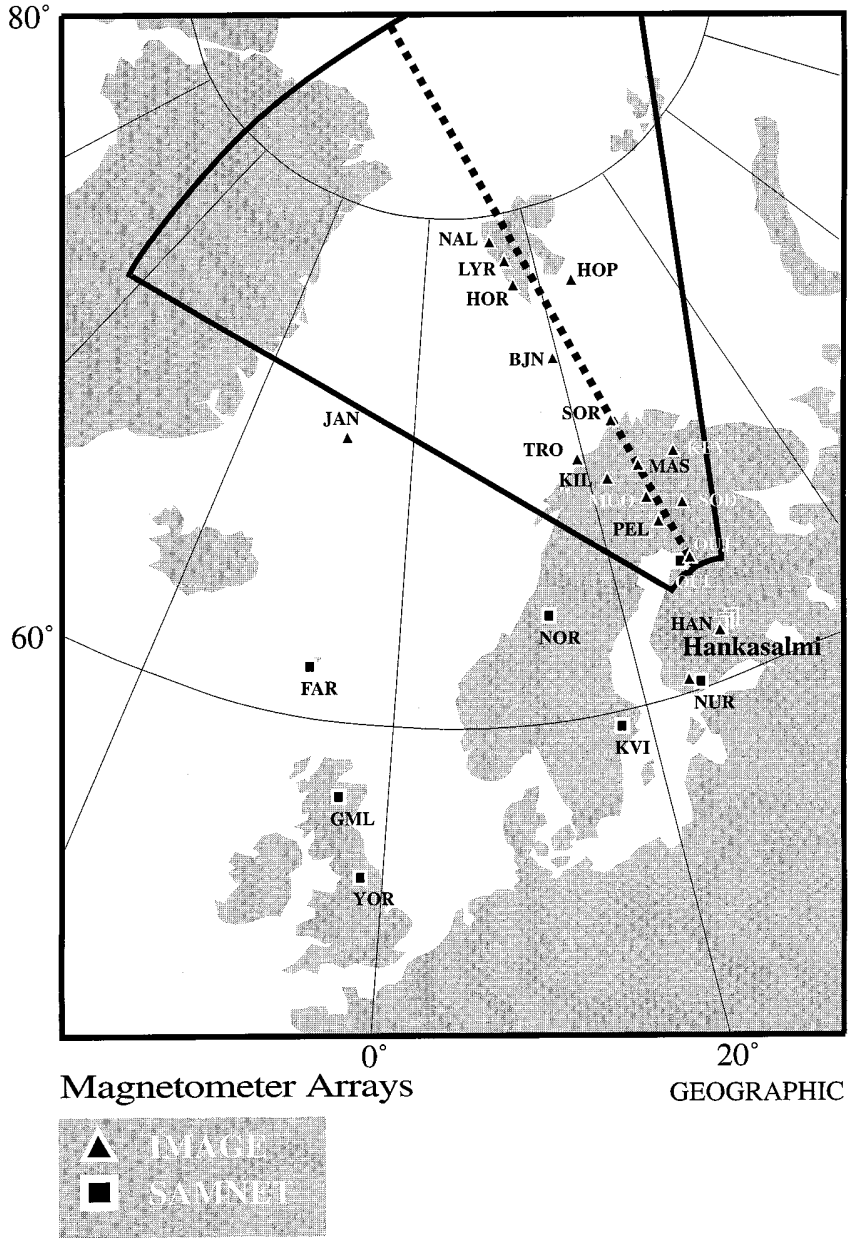

Fig. 1. Locations of the field-of-view of the CUTLASS Finland radar together with the IMAGE and SAMNET magnetometer stations used in this study. Beam 9 of CUTLASS Finland, which is sampled at a high rate, is marked by a dashed line

presented in Fig. 2 along with a field line tracing, using the Tsyganenko T89 model (Tsyganenko, 1990), of an impulsive feature within the CUTLASS Finland field-ofview, discussed in detail in Sect. 4.1.

\section{Observations}

\subsection{Ground-based magnetic response}

Figure 3 presents an overview of the magnetic field data measured by Geotail and IMAGE. Figure $3 \mathrm{a}-\mathrm{d}$ shows the $B_{x}, B_{y}$ and $B_{z}$ components of the magnetic field, between 20:00 and 22:00 UT, measured by the Geotail spacecraft in GSM co-ordinates, and the total field magnitude, respectively. Figure $3 \mathrm{e}-\mathrm{h}$ presents the $X$ component magnetic field from IMAGE stations BJN, SOR, MAS and JAN. Figure $3 \mathrm{i}$ indicates the $X$ component of the ground magnetic field measured at Oulujärvi, Finland, bandpass filtered between 200-40 s $(5-25 \mathrm{mHz})$, to highlight $\mathrm{Pi} 2$ activity. $\mathrm{Pi} 2$ pulsations so identified are marked by vertical lines in the Fig. $3 \mathrm{i}$ at ( \pm 1 minute): 20:08, 20:26, 20:33, and 20:57 UT. The 
T89 field model

06-08-95, 21:00 UT, Kp $=0$

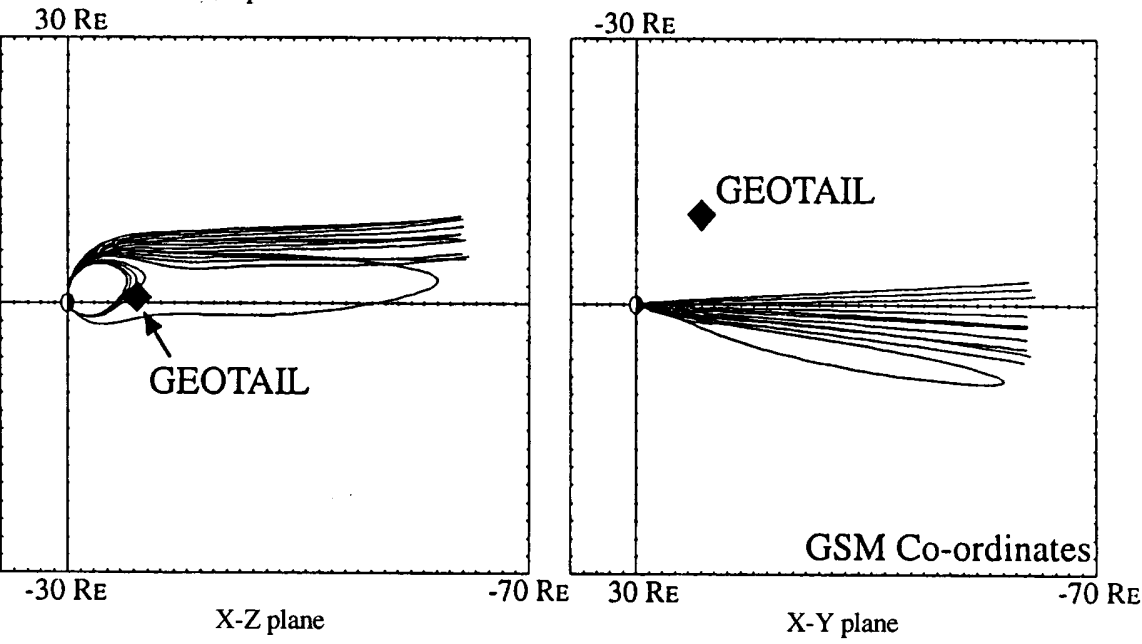

Fig. 2. Magnetic field line mapping in the GSM $X-Z$ and $X$ - $Y$ planes, using T89, of the ionospheric area in the CUTLASS field of view covered by a typical equatorward flowburst at 21:10 UT (see text for details). The location of the Geotail spacecraft is also marked mid-latitude Pi2 measurements are used here to provide a reference onset time for the substorm onsets/intensifications studied in this work (Rostoker et al., 1980).

The mid-latitude $X$ and $Y$ component magnetic field, as well as timing the substorm onset/intensification, have been utilised here to determine the longitudinal position of the substorm current wedge (SCW) for each onset/intensification (see e.g. Lester et al., 1983; Yeoman et al., 1991). The north, $X$, and vertical, $Z$, components of the magnetic field measured by the higher latitude IMAGE stations can be employed in a similar fashion to the SAMNET $X$ and $Y$ component data, to provide information on the location of the substorm-enhanced westward electrojet (e.g. Kisabeth and Rostoker, 1973; Samson and Rostoker, 1983) and hence the latitude of the centre of the electrojet. The high-latitude stations can also give an indication of the longitude of the westward travelling surge.

The mid-latitude magnetometer bay structure (not shown) provides the following picture of the longitudinal development of the substorms during this interval. At 20:08 UT a substorm onset was observed to the east of the ground magnetometers. This onset was not centred near the auroral zone ground-based instrumentation employed in this study and no strong current systems are observed local to these instruments, although the onset may have been close to the local time of the Geotail spacecraft. At 20:26 UT a stronger substorm expansion phase onset signature was observed. The SCW for this event was centred east of the magnetometer arrays, with the upward field aligned current (FAC) between the longitudes of KVI and NUR. An intensification of this substorm occurred at 20:33 UT. Both these onset/intensifications had magnetic signatures of moderately strong current systems near the auroral zone instrumentation. Subsequent to this a small isolated substorm onset signature was observed west of the ground-based instrumentation at 20:57 UT.

In Fig. 3 the IMAGE magnetograms reveal a substorm-enhanced westward electrojet centred between MAS and SOR in the $X$ component magnetic field at
20:26 UT. This is coincident with mid-latitude magnetometer observations of an upward FAC just to the west of the IMAGE stations on Svalbard. The largest electrojet signature observed in the $X$ component for this onset is at SOR. Seven minutes later an intensification of this expansion phase onset is observed, at 20:33 UT. This intensification causes the electrojet centre, deduced from the strongest negative $X$ component perturbation and a positive $Z$ component perturbation of the magnetic field at BJN (not shown), to move poleward to just south of BJN. This intensification has also expanded to the west. The substorm onset indicated by Pi2 activity at 20:57 UT is not very clear in the IMAGE magnetograms. At JAN, however, $25^{\circ}$ to the west, the expected decrease in the $X$ component is observed.

\subsection{Geotail data}

The first significant feature in the magnetic field data at Geotail is the sudden decrease in the magnitude of the $B_{x}$ and $B_{y}$ components seen between 20:14 and 20:19 UT in Fig. 3. There is a decrease in the total field magnitude from $\sim 25 \mathrm{nT}$ to just $\sim 5 \mathrm{nT}$ associated with this change. After 20:19 UT one of the criteria for identifying entry into the inner central plasma sheet (as laid down by Baumjohann et al., 1990), specifically that $\left(B_{x}^{2}+B_{y}^{2}\right)^{1 / 2}$ $<15 \mathrm{nT}$, is consistently fulfilled. After 20:48 UT, both this criterion and the second criterion of Baumjohann et al. (1990), that $B_{z} /\left(B_{x}^{2}+B_{y}^{2}\right)^{1 / 2}>0.5$ are both satisfied. Subsequent to this plasma sheet expansion an interval of very turbulent magnetic field is observed starting at 20:51 UT, in addition to a number of perturbations in all three components of the magnetic field in the $30 \mathrm{~min}$ which follow. It is these features observed within the inner central plasma sheet on which we will concentrate in this study.

Figure 4 presents details of the magnetic field and plasma data between 20:30 and 21:30 UT. Figure 4a-d indicates $B_{x}, B_{y}$ and $B_{z}$ and $B_{\text {total }}$, as in Fig. 3. Figure $4 \mathrm{e}$ 


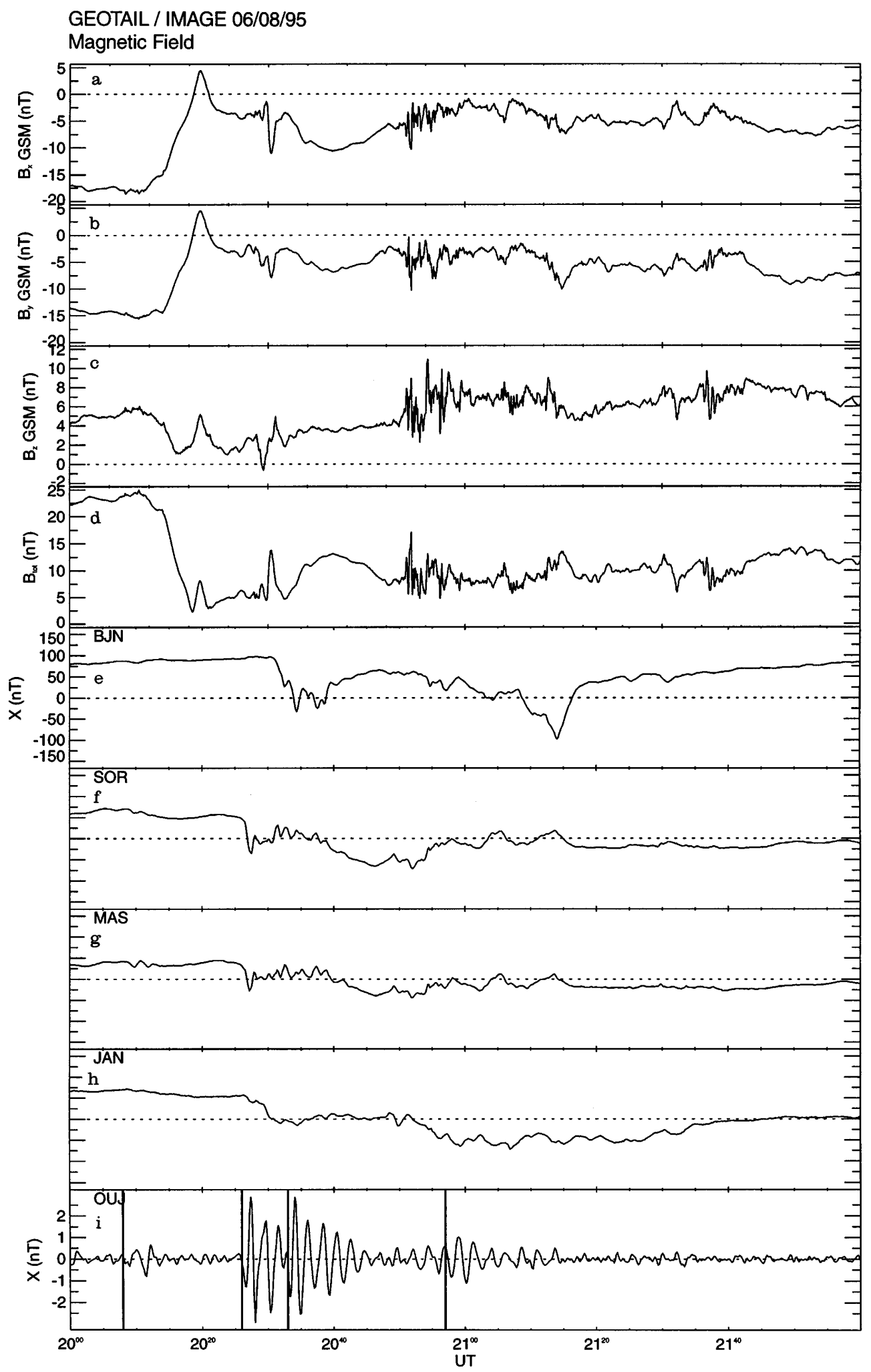

Fig. 3a-d. show the $B_{x}, B_{y}$ and $B_{z}$ components of the magnetic field, between 20:00 and 22:00 UT, measured by the Geotail spacecraft in GSM co-ordinates, and the total field magnitude, respectively. e to $\mathbf{h}$ present the $X$ component magnetic field from IMAGE stations BJN, SOR, MAS and JAN. i shows the $X$ component of the ground magnetic field measured at Oulujärvi, Finland, bandpass filtered between 200 $40 \mathrm{~s}(5-25 \mathrm{mHz})$, to highlight $\mathrm{Pi} 2$ activity. $\mathrm{Pi} 2$ pulsations so identified are marked by vertical lines in $\mathbf{i}$

and $\mathrm{f}$ indicates the GSM $X$ and $Y$ components of the ion bulk drift velocity. The bulk velocity can be seen to be generally low, never exceeding $200 \mathrm{~km} \mathrm{~s}^{-1}$. There are some well-defined perturbations in the observed velocity, however. The first such perturbation coincides with the observations of more rapid, turbulent magnetic field changes at 20:51 UT. Later the fluctuations in velocity coincide with similar frequency fluctuations in the magnetic field. The lower two panels, $g$ and $h$, show the ion density and temperature respectively. The interval of fluctuating magnetic field and ion velocity can be seen to coincide with a decreased ion density and an increased ion temperature measured at the spacecraft. This interval is shaded in Fig. 4. 


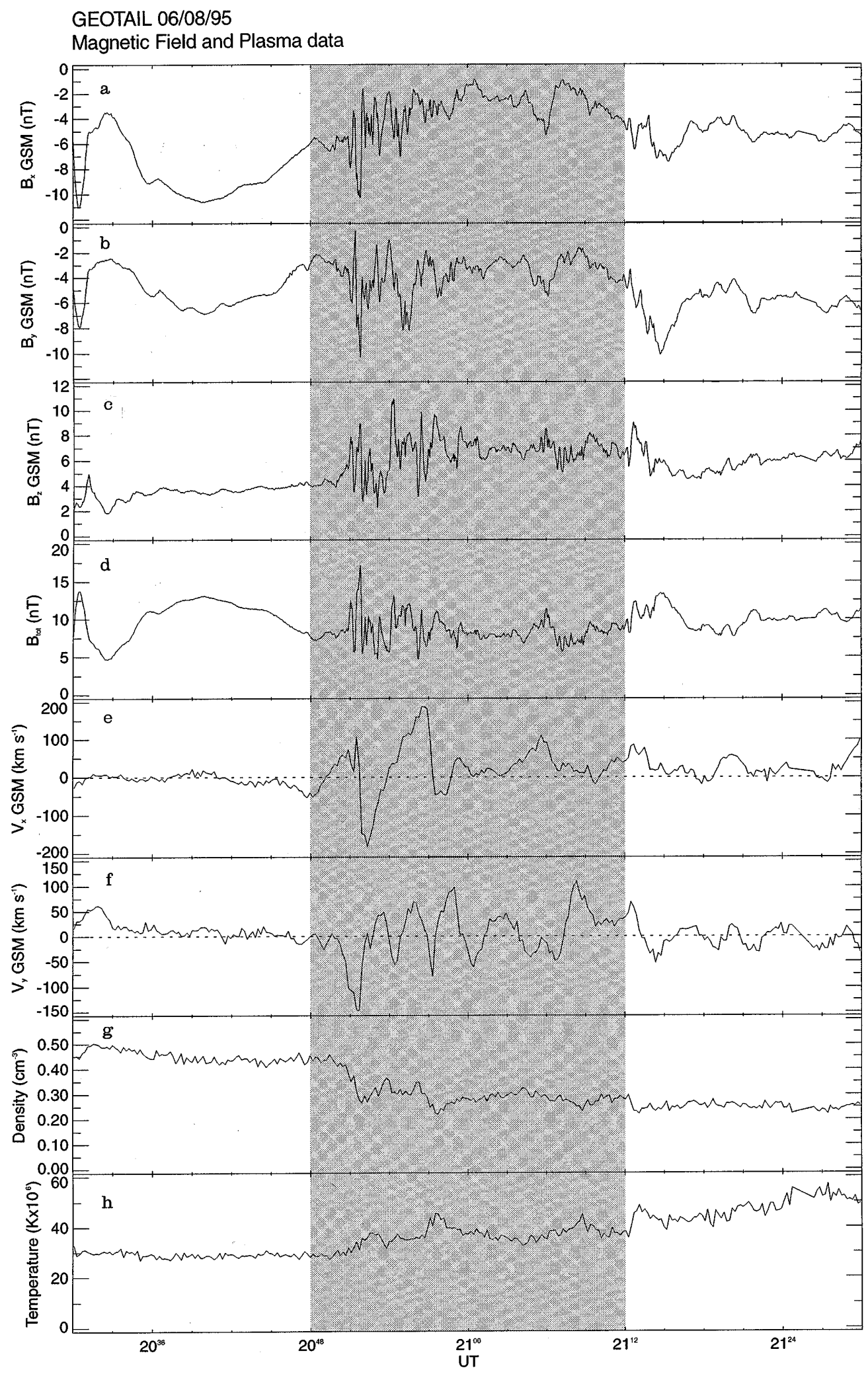

Fig. 4a-h. Details of the magnetic field and plasma data during the interval under study. a-d present $B_{x}, B_{y}$ and $B_{z}$ and $B_{\text {total }}$, as in Fig. 3. e and $\mathbf{f}$ present the GSM $X$ and $Y$ components of the ion bulk drift velocity. $\mathbf{g}$ and $\mathbf{h}$ show the ion density and temperature respectively. The shaded region indicates the interval of fluctuating velocity and magnetic field
Panels a and $b$ of Fig. 5 present the ionospheric convection velocity from the CUTLASS Finland radar. Positive Doppler velocity represents flow toward the radar (equatorward flow). A greyscale representation of the line-of-sight velocity from beam 9 , and a time series plot of beam 9 range gate 25 are displayed. This beam has a sampling rate of $14 \mathrm{~s}$ and points in a meridional direction, and range gate 25 is that which overlies the ground magnetometer station at BJN. The $Y$ component of the magnetic field measured at BJN is displayed in Fig. 5c. The ground-based data is plotted alongside the spacecraft magnetic field and ion velocity 


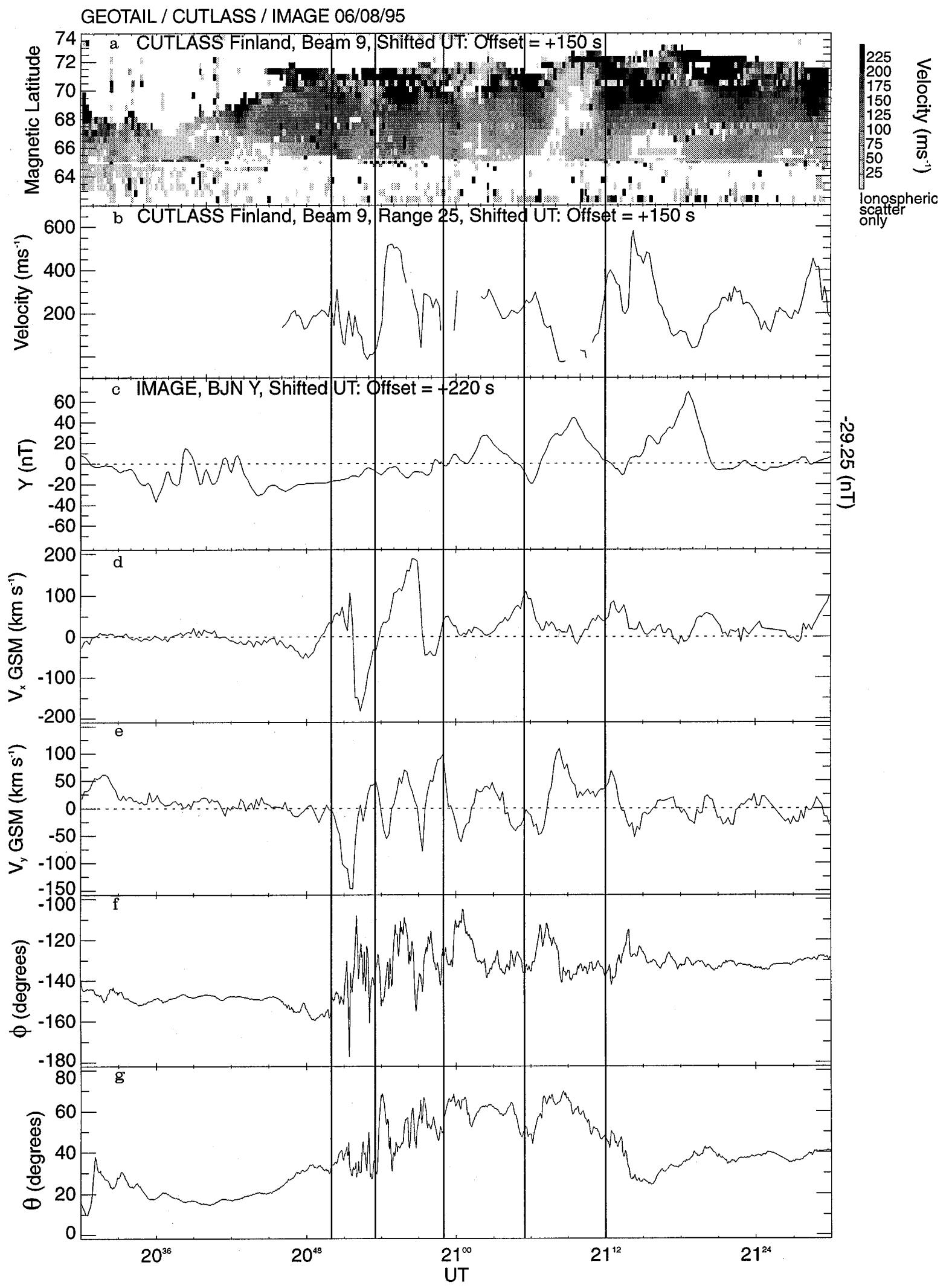

Fig. 5a-g. A comparison of the ground-based and Geotail data. a and $\mathbf{b}$ show the CUTLASS Finland ionospheric convection velocity (positive Doppler velocity represents flow toward the radar, or equatorward flow) in beam 9 of the radar and from the beam-range cell which overlies Bjørnøya (BJN). c presents the $Y$ component of the magnetic field measured at BJN. $\mathbf{d}$ and e display the GSM $V_{x}$ and $V_{y}$ ion velocity measurements. $\mathbf{f}$ and $\mathbf{g}$ represent the magnetic field orientation angles. In $\mathbf{f}, \phi$ is the angle in the GSM $X-Y$ plane, where $-180^{\circ}$ indicates a field pointing in the $-X$ direction and $-90^{\circ}$ the $-Y$ direction. $\mathbf{g}$ displays the field angle from the GSM equatorial plane, $\theta$ 
measurements. Figure 5d, e presents the GSM $V_{x}$ and $V_{y}$ ion velocity measurements respectively. The lower two panels present field orientation angles derived from the magnetic field data. Panel $\mathrm{f}$ presents, $\phi$, the angle in the $X-Y$ plane, where $-180^{\circ}$ indicates a field pointing in the $-X$ direction and $-90^{\circ}$ the $-Y$ direction. Panel $g$ displays the field angle from the GSM equatorial plane, $\theta$.

Any inter-comparison of time series from such widely separated instruments must be adjusted to allow for propagation between the various locations, and the different parameters which are being measured. In Fig. 5 an offset has been applied between the ground-based and spacecraft data to gain optimum agreement between similar features in the convection velocity data and the spacecraft data. The proposed relationship between the ground and spacecraft measurements detailed below is not unambiguous, but we believe it to be highly suggestive of a close link between the observed features. The radar data, taken from instrumentation close to the magnetic local time of the centre of the substorm breakup, lead the Geotail data, and an offset of $+150 \mathrm{~s}$ has been applied to the CUTLASS data. In the detailed study of the ground based signatures presented in Paper 1 , it was demonstrated that the ground magnetometer signature was the response to ionospheric current vortices, and as such was produced by a combination of the imposed ionospheric electric field (which controls the Doppler velocity measured by the radar), and the ionospheric conductivities. Paper 1 demonstrated that the optimum agreement between the velocity and magnetic field signatures from the ground instrumentation occurred when a magnetic field lead of $70 \mathrm{~s}$ was taken into account. Hence an offset of $+220 \mathrm{~s}$ has been applied to the BJN data in Fig. 5.

The main features described here relate to the increased pulses in ionospheric convection velocity illustrated in Fig. 5 a, b at 20:50:00, 20:53:30, 20:59:00, 21:05:30, and 21:12:00 in shifted-UT, as explained already, and marked on Fig. 5 by vertical lines. The ground-based signatures during this interval have been discussed in detail in Paper 1. The first and third of these features are small and were, in fact, not discussed explicitly in Paper 1, but can be identified in their Fig. 3. The last two of these features have a very clear analogue in negative perturbations of the $Y$ component of the magnetic field at $\mathrm{BJN}$, as expected for an equatorward velocity perturbation (poleward conventional current). The first event at 20:50 UT correlates with some characteristic changes in the Geotail magnetic field and plasma data. The magnetic field orientation shows an increase in the angles $\theta$ and $\phi$ at 20:50 UT. The magnetic field changes are accompanied by an increasingly negative $V_{y}$. No systematic behaviour of $V_{x}$ is observed at the five times under study here. These changes represent a dipolarisation of the magnetic field at Geotail, a distortion of the field towards the $-Y$ GSM (dawnwards) direction and an enhanced dawnwards plasma drift. This pattern of behaviour is repeated for each of the other times marked with vertical lines, although no clear dipolarisation is seen for the final interval. The correlation between the magnetic field and plasma data is not completely straightforward. Some intervals of increasingly negative $V_{y}$ are seen at times other than those identified above, but they are not accompanied by clear increases in $\theta$ or $\phi$.

\section{Discussion}

Ground-satellite measurements of transient phenomena occurring during the substorm expansion phase have been presented. The high-latitude ground-based data are recorded close to midnight, less than $1 \mathrm{~h}$ in the premidnight sector. Geotail, at $L \sim 10$, maps to the same magnetic latitude as the ground magnetometer station BJN, but lies some $4 \mathrm{~h}$ MLT to the east. A detailed comparison of the radar and ground magnetometer data, represented in Fig. 5 by the BJN $Y$ component magnetic field time series and the line-of-sight velocity data from the overlying radar beam, has been presented in Paper 1. The present study concentrates on the relationship between these parameters and the spacecraft data. However, a brief review of the deductions made about the ground-based data in Paper 1 is required before an interpretation can be made of the data presented here, and is included in the following section.

\subsection{Expansion phase ionospheric convection}

The dynamic features in the line-of-sight velocity from beam 9, range gate 25 of the CUTLASS Finland radar, which lies close to overhead of BJN, are typically of 5 min duration, with an inter-pulse interval of about $3 \mathrm{~min}$. They peak at a line-of-sight flow of $\sim 600 \mathrm{~m} \mathrm{~s}^{-1}$. The polarities of the $X$ and $Y$ component magnetic field measurements from the IMAGE stations on Svalbard and in northern Scandinavia are qualitatively consistent with the picture of a Hall current vortex from a pair of field-aligned currents. Equivalent current patterns derived from IMAGE stations show at least five vortices centred near BJN, with clockwise and anticlockwise current vortices associated with downward and upward FACs respectively. The deduced time delay between the vortex signatures at the IMAGE stations HOR and HOP implies an eastward propagation speed of $\leq 6 \mathrm{~km}$ $\mathrm{s}^{-1}$, and an azimuthal extent of about $1000 \mathrm{~km}$. The extent of the features in the magnetotail has been estimated using the T89 model, and is illustrated in Fig. 2 for the feature observed between 21:12 and 21:14 shifted-UT in Fig. 5a. T89 offers only a crude mapping of the magnetosphere for such a case study. The model is run here for $K_{p}=0$. The prevailing $K_{p}$ was 2-, but $K_{p}$ had been $\leq 1$ for the entire day up to then, and $K_{p}=0$ is chosen to minimise the field line stretching in T89. The radial extent of the mapping is limited by the limited extent of the radar data at high latitudes. The transient features are detected 15-70 $\mathrm{min}$ after the substorm expansion phase onset. 


\subsection{Geotail data}

The Geotail magnetic field data has shown the spacecraft to enter the inner central plasmasheet at 20:19 UT, presumably as a consequence of the expansion of the plasma sheet resulting from the nearby substorm onset at 20:08 UT. Subsequent to this a number of features in the magnetic field and plasma data at Geotail are suggested to be correlated with the ground observations of azimuthally propagating current vortices some four hours to the west. The corresponding signature in the spacecraft data is a sequence of features showing an increase in the magnetic field angles $\theta$ and $\phi$. Such dipolarisations and variations in $B_{y}$ are consistent with the signatures expected from the magnetospheric field aligned currents associated with the ionospheric current vortices observed by the ground instrumentation. The enhanced dawnwards plasma drift at Geotail is qualitatively consistent with the azimuthal propagation of the ionospheric current vortices.

The combined ground-satellite magnetic field measurements exhibit a similar temporal evolution in the respective $B_{y}$ components on either side of local midnight (compare Figs. 4a and Fig. 5c). The signatures in both sets of instruments also indicate eastwards azimuthal motion. Assuming a common source in the pre-midnight sector, the dawnwards propagating signatures are thus observed first by CUTLASS and then by Geotail. If the azimuthal velocity of $\sim 6 \mathrm{~km} \mathrm{~s}^{-1}$, measured from the ground data in the pre-midnight sector, is appropriate for propagation between the two instruments, then the azimuthal travel time makes up only a small part of the observed delay between the expansion phase onset at 20:26 and subsequent intensification at 20:33 UT and the first observation of the transients.

\subsection{Relationship to substorm theories}

The dynamic variations of ionospheric electric field and currents, localised FAC systems and magnetotail magnetic field and ion velocity perturbations presented here clearly have important implications for the energetics of magnetosphere-ionosphere coupling during substorms. They may also have implications for the substorm onset process in the magnetotail. Although there are a number of competing substorm onset theories (see e.g. Lui, 1991) one of the critical issues of recent years has been whether reconnection at a near-Earth neutral line (NENL, Russell and McPherron, 1973; Hones, 1979) is the cause of eventual substorm breakup in the near-Earth magnetotail (see e.g. Baker et al., 1996 for a recent review) or whether the near-Earth substorm breakup itself triggers subsequent reconnection at a NENL (see e.g. Lui, 1996). There is a considerable body of recent evidence that substorm onset occurs in the very near Earth region, subsequently propagating tailward (Lopez and Lui, 1990; Lopez et al., 1993), with reconnection following in the more distant magnetotail. However other recent studies have suggested that NENL reconnection is the process which initiates substorm onset, with the near-
Earth signatures a consequence of the more distant tail process (e.g. Baker et al., 1993).

The duration, repetition rate and morphology of the impulsive features in the ground-based data presented in Paper 1 is very similar to that of flux transfer events on the dayside (e.g. Lockwood et al., 1990), and this might suggest that the source mechanism is transient reconnection at the NENL. If these features are signs of reconnection they occur some 15-70 min after the substorm expansion phase onset. This delay between expansion phase onset and the observed vortices seems long if the process causing the vortices is directly related to the substorm onset process, although similar delays of $\sim 30$ min have previously been observed between substorm expansion phase onset and polar cap contraction by e.g. Lockwood and Cowley (1992), Yeoman and Pinnock (1996) and Taylor et al. (1996). The transient ionospheric and magnetospheric features may have been produced by earthward flowbursts in the tail (usually termed bursty bulk flows or BBFs) such as those reported by e.g. Baumjohann et al. (1990) and Angelopoulos et al. (1992), although the azimuthal motion suggests they are an inner-magnetosphere response created by such rapid, Earthward plasma flow, rather than related directly to it (see Paper 1). The present Geotail observations were made at the extreme earthward and dawnward limits of previous BBF observations (Baumjohann et al., 1990). The observed velocities are much slower and the magnetic and plasma bulk motion signatures are dominated by azimuthal (dawnward) rather than Sunward perturbations. This is consistent with previous suggestions that the region of rapid flow is spatially localised, confined to a crosssectional area of the tail of 1-2 $R_{E}^{2}$ (Angelopoulos et al., 1996). Angelopoulos and co-workers (1996) also postulated that a deceleration and azimuthal spreading of the Earthward plasma flow would occur in the dipolar region of the nightside magnetosphere, which is directly supported by the observations presented here. Azimuthal perturbations of the magnetic field and velocity measurements associated with BBFs were also discussed by Baumjohann et al. (1990), who suggested an association with the limited azimuthal extent of the flow region. Some evidence of a systematic relationship between the direction of the $V_{y}$ perturbation and the azimuthal location of the observing spacecraft, such that $V_{y}$ was directed away from the midnight sector, has recently been presented by Sergeev et al. (1996) at a distance of $20 R_{E}$ downtail, who interpreted BBFs in terms of plasma sheet bubbles (Chen and Wolf, 1993), probably caused by reconnection in the magnetotail. Indeed, the ground magnetometer features presented here are similar to those of Kauristie et al. (1996), which were again interpreted in terms of plasma sheet bubbles. Some theoretical treatments of the onset mechanism and development of the substorm expansion phase require a breaking and azimuthal redirection of the Earthward plasma flow in the magnetotail (Haerendel, 1992; Shiokawa et al., 1997). The data set presented here supports such theories. Shiokawa et al. (1997), however, did not find any direct evidence for such an azimuthal 
redirection of the Earthward plasma flow in the AMPTE/IRM dataset.

The relative timing and locations of the observations of earthward plasma flows and the substorm breakup region clearly have implications for the sequence of events in the magnetotail which lead to substorm expansion phase onset. The data presented here occur late in the substorm growth phase. It remains possible, however, that similar features occurred in the growth phase of the substorm expansions studied here. The examination of a larger dataset will be required to address such issues in more detail.

\section{Conclusions}

Data from the CUTLASS Finland HF radar with a temporal resolution of $14 \mathrm{~s}$ have revealed pulses of equatorward flow during the substorm expansion phase. These flow pulses exceed $\sim 600 \mathrm{~m} \mathrm{~s}^{-1}$ and are observed with a duration of $\sim 5 \mathrm{~min}$, a repetition period of $\sim 8 \mathrm{~min}$ and an eastward azimuthal propagation of $\leq 6 \mathrm{~km} \mathrm{~s}^{-1}$. Each pulse of enhanced equatorward flow was preceded by an interval of suppressed flow and enhanced ionospheric Hall conductance. These transient features are interpreted as being due to ionospheric current vortices associated with field aligned current pairs generated during the substorm expansion phase. The present study reveals that these ionospheric convection features appear to have an accompanying signature, comprising a dawnward perturbation and dipolarisation of the magnetic field and dawnward plasma flow, measured in the geomagnetic tail by the Geotail spacecraft, located at $L=10$ and some four hours to the east, in the postmidnight sector. These signatures are suggested to be due to the observation of the same field aligned currents in the magnetosphere. They are suggested to be related to the deceleration and azimuthal diversion of bursty Earthward plasma flow during the substorm expansion phase. The case study results presented here are not conclusive, but further opportunities to make similar measurements should occur soon, following the successful launch of the Equator-S mission.

Acknowledgements. We would like to thank Dave Milling, University of York, for providing the SAMNET data, Hermann Lühr for providing the IMAGE data and Rumi Nakamura for providing the Geotail MGF data. The CUTLASS HF radars are deployed and operated by the University of Leicester, and are jointly funded by the UK Particle Physics and Astronomy Research Council, the Finnish Meteorological Institute, and the Swedish Institute for Space Physics.

Topical Editor K. H. Glaßmeier thanks, V. F. Angelopoulous and K. Kauristie for their help in evaluating this paper.

\section{References}

Angelopoulos, V., W. Baumjohann, C. F. Kennel, F. V. Coroniti, M. G. Kivelson, R. Pellat, R. J. Walker, H. Lühr, and G. Paschmann, Bursty bulk flows in the inner central plasma sheet, J. Geophys. Res., 97, 4027-4039, 1992.
Angelopoulos, V., F. V. Coroniti, C. F. Kennel, M. G. Kivelson, R. J. Walker, C. T. Russell, R. L. McPherron, E. Sanchez, C.-I. Meng, W. Baumjohann, G. D. Reeves, R. D. Belian, N. Sato, E. Friis-Christensen, P. R. Sutcliffe, K. Yumoto, and T. Harris, Multipoint analysis of a bursty bulk flow event on April 11, 1985, J. Geophys. Res., 101, 4967-4989, 1996.

Baker, D. N., T. I. Pulkkinen, R. L. McPherron, J. D. Craven, L. A. Frank, R. D. Elphinstone, J. S. Murphree, J. F. Fennel, R. E. Lopez, and T. Nagai, CDAW 9 analysis of magnetospheric events on May 3, 1986: event C, J. Geophys. Res., 98, 38153834, 1993.

Baker, D. N., T. I. Pulkkinen, V. Angelopoulos, W. Baumjohann, and R. L. McPherron, Neutral line model of substorms: past results and present view, J. Geophys. Res., 101, 12,975-13,010, 1996.

Baumjohann, W., G. Paschmann, and H. Lühr, Characteristics of high-speed ion flows in the plasma sheet, J. Geophys. Res., 95, 3801-3809, 1990.

Chen, C. X., and R. A. Wolf, Interpretation of high-speed flows in the plasma sheet, J. Geophys. Res., 98, 21,409-21,419, 1993.

Greenwald, R. A., K. B. Baker, J. R. Dudeney, M. Pinnock, T. B. Jones, E. C. Thomas, J.-P. Villain, J.-C. Cerisier, C. Senior, C. Hanuise, R. D. Hunsucker, G. Sofko, J. Koehler, E. Nielsen, R. Pellinen, A. D. M. Walker, N. Sato and H. Yamagishi, Darn/ Superdarn: a global view of the dynamics of high-latitude convection, Space Sci. Rev., 71, 761-796, 1995.

Haerendel, G., Disruption, ballooning or auroral avalanche - on the cause of substorms, Proc. ICS-1, ESA SP-335, 417-420, 1992.

Hones, E. W. Jr., Transient phenomena in the magnetotail and their relation to substorms, Space Sci. Rev., 23, 393-410, 1979.

Kauristie, K., V. A. Sergeev, T. I. Pulkkinen, R. J. Pellinen, V. Angleopoulos, and W. Baumjohann, Study on the ionospheric signatures of the plasma sheet bubbles, Proc. ICS-3, ESA SP389, 93-98, 1996.

Kirkwood, S., H. J. Opgenoorth, and J. S. Murphree, Ionospheric conductivities, electric fields and currents associated with auroral substorms measured by the EISCAT radar, Planet. Space Sci., 36, 1359-1380, 1988.

Kisabeth, J. L., and G. Rostoker, Current flow in auroral loops and surges inferred from ground-based magnetic observations, J. Geophys. Res., 78, 5573-5584, 1973.

Kokubun, S., T. Yamamoto, M. H. Acuna, K. Hayashi, K. Shiokawa, and H. Kawano, The GEOTAIL magnetic field experiment, J. Geomagn. Geoelectr., 46, 7-21, 1994.

Lester, M., W. J. Hughes, and H. J. Singer, Polarization patterns of Pi2 magnetic pulsations and the substorm current wedge, J. Geophys. Res., 88, 7958-7966, 1983.

Lockwood, M., and S. W. H. Cowley, Ionospheric convection and the substorm cycle, Proc. Int. Conf. on Substorms, ESA SP-335, 99-109, 1992.

Lockwood, M., S. W. H. Cowley, P. E. Sandholt, and R. P. Lepping, The ionospheric signatures of flux transfer events and solar wind dynamic pressure changes, J. Geophys. Res., 95, 1711317135, 1990.

Lopez, R. E., and A. T. Y. Lui, A multisatellite case study of the expansion of a substorm current wedge in the near-earth magnetotail, J. Geophys. Res., 95, 8009-8017, 1990.

Lopez, R. E., H. E. J. Koskinen, T. I. Pulkkinen, T. Bösinger, R. W. McEntire, and T. A. Potemra, Simultaneous observation of the poleward expansion of substorm electrojet activity and the tailward expansion of current sheet disruption in the near-Earth magnetotail, J. Geophys. Res., 98, 9285-9295, 1993.

Lühr, H., The IMAGE magnetometer network, STEP Int. Newsl., 4, (10), 4-6, 1994.

Lühr, H., and K. Schlegel, Combined measurements of EISCAT and the EISCAT magnetometer cross to study $\Omega$ bands, J. Geophys. Res., 99, 8951-8959, 1994.

Lühr, H., M. Lockwood, P. E. Sandholt, T. L. Hansen, and T. Moretto, Multi-instrument ground-based observations of a travelling convection vortices event, Ann. Geophysicae, 14, 162-181, 1996. 
Lui, A. T. Y., A synthesis of magnetospheric substorm models, J. Geophys. Res., 96, 1849-1856, 1991.

Lui, A. T. Y., Current disruption in the Earth's magnetosphere: observations and models, J. Geophys. Res., 101, 13,067-13,088, 1996.

Morelli, J. P., R. J. Bunting, S. W. H. Cowley, C. J. Farrugia, M. P. Freeman, E. Friis-Christensen, G. O. L. Jones, M. Lester, R. V. Lewis, H. Lühr, D. Orr, M. Pinnock, G. D. Reeves, P. J. S. Williams and T. K. Yeoman, Radar observations of auroral zone flows during a multiple-onset substorm, Ann. Geophysicae, 13, 1144-1163, 1995.

Mukai, T., S. Machida, Y. Saito, M. Hirahara, T. Terasawa, N. Kaya, T. Obara, M. Ejiri, and A. Nishida, The low energy particle (LEP) experiment onboard the GEOTAIL satellite, J. Geomagn. Geoelectr., 46, 669-692, 1994.

Rostoker, G., S.-I. Akasofu, J. Foster, R. A. Greenwald, Y. Kamide, K. Kawasaki, A. T. Y. Lui, R. L. McPherron, and C. T. Russell, Magnetospheric substorms - definition and signatures, J. Geophys. Res., 85, 1663-1668, 1980.

Russell, C. T., and R. L. McPherron, The magnetotail and substorms, Space Sci. Rev., 15, 205-266, 1973.

Samson, J. C., and G. Rostoker, Polarization characteristics of Pi2 pulsations and implications for their source mechanisms: influence of the westward travelling surge, Planet. Space Sci., 31, 435-458, 1983

Sergeev, V. A., V. Angelopoulos, J. T. Gosling, C. A. Cattell, and C. T. Russell, Detection of localized, plasma-depleted flux tubes or bubbles in the midtail plasma sheet, J. Geophys. Res., 101, 10 817-10 826, 1996.

Shiokawa, K., W. Baumjohann, and G. Haerendel, Braking of high speed flows in thenear-Earth tail, Geophys. Res. Lett., 24, 11791182, 1997.

Taylor, J. R., T. K. Yeoman, M. Lester, B. A. Emery, and D. J. Knipp, Variations in the polar cap area during intervals of substorm activity on March 20-21 1990 deduced from AMIE convection patterns, Ann. Geophysicae, 14, 879-887, 1996.

Tsyganenko, N. A., Quantitative models of the magnetospheric magnetic field: methods and results, Space Sci. Rev., 54, 75-186, 1990.

Yeoman, T. K., and M. Pinnock, The high-latitude convection response to an interval of substorm activity, Ann. Geophysicae, 14, 518-532, 1996.

Yeoman, T. K., and H. Lühr, CUTLASS/IMAGE observations of high-latitude convection features during substorms, Ann. Geophysicae, 15, 692-702, 1997.

Yeoman, T. K., D. K. Milling, and D. Orr, Pi2 pulsation polarization patterns on the UK Sub-auroral Magnetometer Network (SAMNET), Planet. Space Sci. 38, 589-602, 1990.

Yeoman, T. K., M. Lester, D. K. Milling and D. Orr, Polarization, propagation and MHD wave modes of $\mathrm{Pi} 2$ pulsations: SABRE/ SAMNET results, Planet. Space Sci, 39, 983-998, 1991. 